\title{
Relativo ma non troppo: de novo a favor da Objectividade na Execução Musical
}

\author{
António Lopes \\ Universidade de Lisboa e Grupo LanCog \\ BIBLID [0873-626X (2012) 34; pp. 739-753]
}

\section{Introdução}

Uma tese largamente difundida e aceite na comunidade musicológica é a de que os juízos de valor em música são fundamentalmente uma questão de gosto subjectivo moldado pelo contexto músico-cultural e pela tradição. Esta tese é principalmente reflectida nas análises de obras musicais, mas é facilmente transponível para o domínio da execução de tais obras, no qual ela consiste basicamente numa forma de pluralismo interpretativo, isto é, a ideia de que há várias interpretações incompatíveis de cada obra igualmente correctas e (esteticamente) boas, não havendo uma interpretação que seja a única maximamente correcta e boa. ${ }^{1}$

Esta situação contrasta com duas práticas bem estabelecidas na cultura musical actual no domínio da música clássica da tradição ocidental: a dos concursos para intérpretes e a da crítica de execuções, quer ao vivo, quer gravadas. Neste último domínio, em particular,

\footnotetext{
${ }^{1}$ Um exemplo: "I would like [...] to propose an indefinite moratorium on equations of analysis and value judgement, and indeed more broadly on equations of academic research and aesthetic approval. [...] It seems to me that the idea of the musical academy acting as some kind of quality control, with musicologists or theorists issuing admission tickets to a canonic hall of fame, is way past its sellby date, and that the prerequisite for a more open-minded approach to musical culture than musicology has traditionally had is a more modest intellectual ambition: to register, to describe, to establish the facts as they are. [...] Of course, we cannot entirely eliminate our sense of what is good and bad from our professional work. But we can make a conscious attempt to moderate its influence" (Cook 2003: 261).
}

Disputatio, Vol. IV, No. 34, December 2012 
existe uma grande abundância de produção quotidiana de tipo mais ou menos jornalístico, evidentemente com níveis diferentes de competência e exigência. Como todas as actividades críticas, esta supõe a crença nalgum grau de objectividade nos juízos de valor estético, sem o qual não faria sentido que o crítico, para além de descrever uma execução, se pronunciasse quanto ao seu valor. De modo razoavelmente compreensível, são muitos os musicólogos que encaram com grande desconfiança uma actividade que não só é quase sempre pouco académica e científica, como ainda para mais adopta, implícita ou explicitamente, critérios de objectividade ou monismo estético. Tal desconfiança explica a recepção fria e talvez um pouco paternalista concedida por essa comunidade aos poucos estudos musicológicos com credenciais académicas que tentam demonstrar, mediante a análise musical, que algumas escolhas interpretativas são melhores do que outras na medida em que se adequam melhor à obra a executar. ${ }^{2}$ Quanto aos concursos, eles são geralmente rejeitados, e não só por musicólogos, como eventos com um certo carácter circense, de interesse para a psicologia e a sociologia da música, nos quais pouco mais do que a habilidade técnica - e não o valor interpretativo - é apreciado e classificado.

Se afastarmos as razões de falta de competência, experiência, informação, sensibilidade ou parcialidade que colocam a maioria dos críticos de execuções de obras musicais num patamar demasiado abaixo do representado pela fasquia do crítico ideal de Hume, põese o problema: serão todas, ou pelo menos a grande maioria, das opções interpretativas, em última análise, igualmente defensáveis, sendo assim o seu valor estético ou artístico irremediavelmente relativo? Neste ensaio, e no seguimento de uma crítica anterior (Lopes 2006) às posições relativistas de Jerrold Levinson (Levinson 1987), defenderei uma resposta negativa, sugerindo que, à semelhança do que é defendido por muitos acontecer nas artes em geral, ${ }^{3}$ há um

\footnotetext{
${ }^{2}$ Dois exemplos são Berry (1989) e Narmour (1988)

${ }^{3}$ Esta tese pode ser lida como pressupondo que se está a tratar execuções musicais (produto) como obras de arte. No entanto, é possível limitarmo-nos ao pressuposto mais fraco e pacífico de que elas (acto e/ou produto) são, pelo menos, arte - parte da arte musical. Para uma boa defesa de ambas as ideias, ver Kivy 1995, 122 ss.
} 
espectro de objectividade ou universalidade na aceitação de juízos sobre o valor de execuções musicais, que vai de um extremo de objectividade (quase) total ao da relatividade (muito provavelmente) total. Para essa defesa serão apresentados alguns exemplos de domínios da execução musical nos quais certas estratégias ou escolhas interpretativas são claramente preferíveis a outras, sendo que, se essas o são, outras o poderão ser também. Os exemplos pretendem ser válidos pelo menos para a música tonal-modal, embora a sua transposição para algumas outras linguagens musicais da tradição ocidental seja relativamente linear. Isto bastará para demonstrar a falsidade da tese mencionada no início, e apoiar uma forma de monismo ou objectivismo molto moderato no campo da execução musical, alicerçado em princípios estéticos que, embora reconhecidos como suplantáveis ou fracos, no sentido de Sibley, ${ }^{4}$ são, ainda assim, princípios.

\subsection{Textura e condução de vozes: polifonia versus melodia} acompanhada

Uma distinção básica que abrange a maioria das obras da tradição ouvidas nas nossas salas de concerto diz respeito à textura da música. Por um lado, temos música que consiste numa voz principal, de carácter melódico, acompanhada por outras subordinadas, geralmente com ritmos e desenhos uniformes e relativamente simples, que as aglutinam entre si (usualmente em acordes, arpejados ou não) num plano de fundo e as distinguem da melodia. Um bom exemplo disso será uma secção de uma peça para piano do classicismo.

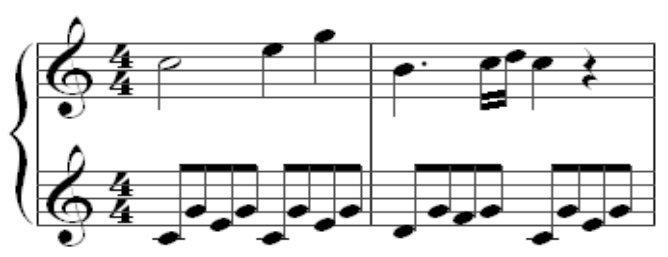

W.A. Mozart: Início da Sonata em Dó maior K. 545

${ }^{4}$ Sibley 1989 
Por outro lado, temos as texturas polifónicas, em que as várias vozes gozam de grande independência nos planos rítmico e melódico, ainda que uma delas - por exemplo, a mais aguda - possa ser auditivamente seguida com maior facilidade. Para além disso, este tipo de textura articula-se muito frequentemente em função de temas (e contra-temas ou respostas), geralmente enunciados na entrada de cada voz, e do contraste entre, por um lado, momentos mais marcados pela presença desses temas etc., e, por outro, episódios mais, ou completamente, livres. Um bom exemplo disso será uma fuga barroca.

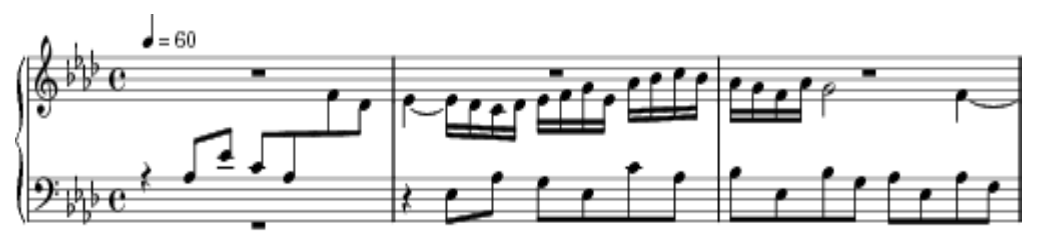

J. S. Bach: Fuga 17 do Cravo Bem Temperado, Livro I

Dadas estas duas texturas contrastantes, parece evidente que a escolha interpretativa que melhor as serve, e que é seguida por quase todos os intérpretes e educadores, consiste em dar maior saliência à voz que tem um papel mais destacado em cada uma dessas texturas. Assim, na melodia acompanhada, a melodia deverá prevalecer durante a maior parte do tempo, enquanto na fuga são as várias entradas das vozes que serão destacadas enquanto enunciam o tema, diminuindo de seguida a atenção a elas dada (o contratema beneficiará geralmente de uma saliência moderada, estando o tema simultaneamente presente noutra voz). Em geral, o destaque é gerido em função do material temático e da relação que a sua presença numa voz estabelece entre essa e as restantes vozes. Por exemplo, num stretto, em que as vozes entram com o tema começando na voz seguinte antes de a voz anterior ter acabado de enunciar o tema completo, sugerindo a imagem de um "atropelo" com acumulação de tensão, teremos de moderar a saliência de uma voz antes de ela terminar o tema. Por outro lado, secções da música em que não é apresentado o tema (nem o contratema) merecem menos destaque global.

É um facto que há regras específicas de cada contexto histórico- 
musical que se aplicam à execução das obras nele criadas em termos de textura. No entanto, elas indicam-nos o modo de efectivar a estratégia interpretativa que é julgado adequado nesse contexto, e não que não deve haver distinção de relevância entre as vozes. Por exemplo, o modo mais óbvio de concretizar a hierarquia de vozes e/ou material temático é através da dinâmica: uma voz será ouvida como mais importante se soar mais forte do que as restantes. Este não é contudo o único meio, embora seja o menos subtil e mais eficaz. Ora, certos instrumentos, como o cravo e o órgão, não permitem tocar com maior volume as diferentes vozes que são tocadas no mesmo teclado. Contudo, a regra aplica-se aí também, com a diferença de que a saliência deverá ser realizada através da articulação (mais ligado ou mais destacado) e do rubato (pequenos atrasos ou acelerações). Por outro lado, o cravo, ou pelo menos alguns cravos, beneficiam também de uma diferenciação tímbrica de registos dentro de um mesmo teclado que, de um modo subtil mas real para o ouvido experiente, contribui para a hierarquização das vozes na ausência do recurso da dinâmica. Aliás, o modelo da forma polifónica é, em grande parte do repertório, e certamente no anterior ao séc. XIX, a música vocal, e nesta é sempre possível, por recursos dinâmicos, agógicos, tímbricos e outros, conferir destaque à voz ou vozes desejadas.

Do mesmo modo, também no caso da textura de melodia acompanhada há pelo menos uma escolha interpretativa - dar ou não relevo à melodia (principal) - que quase não é escolha alguma, na medida em que não o fazer seria visto como falta grave de musicalidade, ou mesmo incompreensão da natureza da obra musical ou do excerto em causa. Este carácter objectivo e artisticamente imperioso da atenção à melodia na textura em questão reforça pelo menos um monismo interpretativo moderado, sendo contudo certamente compatível com o relativismo em outros aspectos relacionados. Assim, a importância da melodia tem de ser evidente, ainda que haja momentos em que faz sentido suavizá-la um pouco em proveito de algo musicalmente relevante a ocorrer simultaneamente numa melodia secundária ou mesmo na estrutura harmónica ou rítmica do acompanhamento. Além disso, diferentes intérpretes valorizarão de diferentes maneiras as melodias secundárias eventualmente formadas no seio do acompanhamento, de entre as quais devemos ainda distinguir as que mais claramente foram intencionadas como melodias de algum relevo pelo 
compositor e aquelas que o próprio intérprete realmente descobre na textura. Finalmente, aqui como no caso da textura polifónica, o repertório de meios musicais que é possível empregar na diferenciação e condução de vozes está mais ou menos objectivamente delimitado, mas as escolhas dentro desses limites fazem parte do domínio da liberdade artística do intérprete, com resultados por vezes mais, por vezes menos, difíceis de antever num raciocínio indutivo, i.e., mais ou menos regrados por princípios universalizáveis, tal como sucede com a escolha dos meios usados para realçar os temas ou para assinalar a diferença entre exposição e episódio numa fuga.

Repare-se que este tipo de escolha interpretativa está alicerçado em propriedades do conteúdo melódico e rítmico da própria músi$\mathrm{ca}$ - incluindo as características gerais que fazem de algo uma (boa) melodia tonal ou modal - e em realidades da nossa percepção auditiva - não é possível ter sempre a mesma atenção auditiva a todas as vozes, ou pelo menos, não é desejável interpretá-las desse modo -, e não em padrões de gosto pessoal ou contextual. Todo o ouvinte competente deve ouvir como monótona, para além de confusa, uma execução que apresente a obra como desprovida de qualquer destaque e diversidade nos parâmetros referidos. ${ }^{5}$ Podemos então falar, parece, de um princípio consideravelmente geral que poderíamos baptizar como "o que é interessante deve ser relevado", de onde se derivam princípios mais específicos como o relativo à execução de música com as texturas que acabamos de analisar. A projecção da sinergia entre informação e diferenciação conseguida mediante a aplicação destes princípios mais específicos poderia ser interpretada, em termos dos cânones de Beardsley, como favorecendo um equilíbrio entre variedade e unidade que resultará numa maior intensidade expressiva. Assim, não faria sentido alguém usar este tipo de diferenciação, quando aplicado correctamente, i.e., às vozes correctas nos momentos correctos, como razão para justificar um juízo estético negativo sobre a execução em causa.

\footnotetext{
${ }^{5}$ Tal opção pode ser uma virtude em casos como o de alguma música minimal repetitiva, e talvez em algumas obras neo-clássicas, mas trata-se evidentemente de excepções.
} 


\subsection{Clarificação da textura orquestral}

Outro princípio específico relativamente ao qual parece haver uma larga concordância entre críticos, senão mesmo unanimidade, entre músicos e críticos, é a de que uma execução de música de conjunto, com especial relevo para a orquestral, que consegue clarificar em grau elevado a textura, os timbres, as vozes polifónicas e suas gradações dinâmicas, etc., é, ceteris paribus, uma melhor execução do que uma que não o consegue ou o consegue em grau inferior.

Para avaliarmos esta tese, convém situarmo-nos num segmento do repertório em que poderia parecer que tais qualidades são, não uma virtude, mas um defeito da execução. Tanto quanto me é dado ver, o melhor candidato seria, por exemplo, uma obra orquestral grandiosa, sombria e solene do romantismo tardio. ${ }^{6}$ Quando é que a clarificação das texturas seria uma falha na sua execução? Apenas, parece-me, se essa clarificação for inevitavelmente prejudicial a valores importantes para o estilo em causa (por exemplo, a sensação de peso orquestral, especialmente nos graves, a grandiosidade e a acumulação/resolução de tensão nos clímaxes, o carácter vibrante e o vibrato propriamente dito) e não trouxer outros atributos ao nível dos elementos da textura que evidencia ao clarificar, que possam contrabalançar as perdas nos elementos importantes acima referidos. Assim sendo, esta excepção é de certo modo também ela dotada de regras, não estando completamente mergulhada em relativismo. De qualquer modo, em todos os outros casos, que são a grande maioria, parece absurdo afirmar que uma dada execução é pior pelo facto de clarificar a textura polifónica de uma obra - mesmo a de uma do repertório acima mencionado, sendo a dificuldade em obter nela tal clareza muitas vezes um factor de desafio aos intérpretes que lhes granjeia mérito adicional da parte da crítica, no caso de serem bem

${ }^{6}$ Para quem não possa passar sem um exemplo concreto, talvez a 8 a Sinfonia de Bruckner, ou a maior parte das passagens orquestrais do Crepúsculo dos Deuses, de Wagner. A sugestão da música orquestral do impressionismo francês poderia parecer ser também um terreno adequado para a colheita de contra-exemplos. No entanto, ele é menos propício do que é aparente, dada a preferência dos compositores franceses (especialmente Ravel) e dos seus intérpretes nativos por texturas transparentes e pouco pastosas, e pela moderação nos tempi, como noutros parâmetros. 
sucedidos. Afirma-se, isso sim, que uma tal execução é má porque, à força de querer clarificar texturas, perde em características do tipo das acima referidas no repertório adequado e quando estas têm um peso elevado. ${ }^{7}$ Se tudo permanecer igual, porém, uma execução só poderá, em geral, ser melhor por obter essa clarificação, expondo à atenção do público mais detalhes composicionais interessantes que de outra forma permaneceriam obscurecidos. Com efeito, é até defensável que mesmo nos casos em que a clarificação revele alguma superficialidade ou falta de sofisticação na textura de uma obra, a revelação seja ainda um mérito enquanto qualidade da execução, por nos permitir analisar e avaliar com mais informação e maior correcção e justiça a obra executada. ${ }^{8}$

Um bom exemplo da quase universalidade deste tipo de preferência pode ser encontrado no sucesso do chamado movimento da "interpretação historicamente informada" (ou, no seu infeliz título original, felizmente evitado hoje em dia, movimento da "interpretação autêntica”). A procura dos meios e estilos de execução que repliquem as condições originais dos contextos de criação e estreia das obras teve certamente a seu favor muitos componentes de carácter ideológico. ${ }^{9}$ No entanto, com o passar do tempo e a perspectiva histórica sobre o próprio movimento, podemos afirmar com segurança que as marcas características que ele nos trouxe de novo face ao paradigma tardo-romântico - entre outras, texturas mais transparentes, articulação mais pronunciada, maior relevo de tempos fortes no compasso, grande atenção ao texto cantado - não só foram acolhidas por praticamente todos os intérpretes desse reportório e pelo público, passando a ser a norma, como inclusivamente transbordaram as fronteiras da música pré-romântica, tornando-se, algumas delas, exigências genéricas, ainda que naturalmente com maior incidência em certos repertórios do que noutros.

\footnotetext{
${ }^{7}$ Uma possível excepção - mas apenas possível - será a de obras como algumas de Ligeti ou Penderecki num estilo geralmente apelidado de música de texturas.

${ }^{8}$ Para um desenvolvimento e defesa da ideia de que há propriedades de valor positivo nas execuções de obras que não derivam directamente de propriedades, positivas ou não, das obras executadas, ver Lopes 2005.

${ }^{9}$ Desenvolvo este e muitos outros aspectos do movimento em Lopes 2010, cap. 10 .
} 
Não parece tratar-se somente de uma questão de gosto actual, uma vez que mesmo o público melómano (provavelmente) minoritário hoje em dia que aprecia as suas execuções das obras relevantes do romantismo tardio servidas com uma dose extra de peso orquestral, profundidade expressiva, timbres escuros e carácter sombrio, e o não tão minoritário grupo a quem desagrada a excessiva leveza e brancura de algumas vozes agudas típicas dos primeiros passos do movimento em causa, não deseja ver sacrificados a esses valores mais subjectivos os méritos mais universais, na dose certa, que o sucesso do movimento trouxe, por arrastamento, ao repertório em causa. ${ }^{10}$ $\mathrm{Na}$ verdade, as vozes críticas em relação a alguns resultados do movimento, que não as motivadas apenas pela falta de hábito, erguem-se quase sempre contra o exagero nalgumas características e opções do mesmo que põem em causa o equilíbrio relativamente a outros valores também eles consensuais. ${ }^{11}$ Mesmo a excepção mais evidente nesse sucesso dos instrumentos e práticas contextuais, a resistência à substituição do piano pelo fortepiano no repertório que vai do clas-

${ }^{10}$ Peço a compreensão do leitor para esta aparentemente abusiva assunção da legitimidade para falar em nome dessa(s) minoria(s) com a confissão de que se houvesse uma estrutura institucional para tal sensibilidade em matéria de execução musical, eu seria provavelmente um dos seus membros fundadores.

${ }^{11}$ A este título, refira-se como exemplo a nostalgia bastante compreensível pelas execuções da música sacra de Bach por intérpretes da antiga mainstream como Karl Richter, patente por exemplo nas páginas da revista de referência Gramophone (em especial, as assinadas pelo crítico da especialidade, Jonathan Freeman-Attwood). Essa crítica às execuções "historicamente informadas" não se daria se não fossem as falhas de várias execuções desse tipo dos nossos tempos (mas sobretudo dos anos 80 e princípio de 90) em termos de expressividade na enunciação dos textos, que parece sacrificada à uniformidade e à segurança técnica mais ou menos asséptica (para além de algum sentimento de banalização da arte, patente na ideologia do movimento inicial, que se pode materializar de modo infeliz nessas características, e em casos como a admissão ao estatuto de execução profissional de intérpretes que não estão à altura das exigências, em virtude da "especialização" ou de atractivos até certo ponto extra-musicais (caso de muitos contra-tenores substituindo meio-sopranos e contraltos bem mais seguros e competentes, graças à aura de historicidade da técnica do falsetista - cf. nota 9). Ou seja, não tem de haver incompatibilidade de princípio entre os valores da execução musical estabelecidos, como os da musicalidade e da expressividade, e a clareza de texturas e articulação, etc., ainda que a harmonização entre essas duas "classes" de valores seja na prática difícil de conseguir (se é que o é de facto). 
sicismo até meados do séc. XIX, parece mostrar uma certa consistência e selectividade saudável no acolhimento das "novidades" da "interpretação historicamente informada", e até ser sintomática do que tenho vindo a expor. A menor aceitação pública do instrumento como alternativa ao piano moderno (não estou a falar do meio da musicologia histórica, naturalmente) mostra que não é desejável a clareza e leveza a qualquer preço, e que, para além de um som pouco consensual da parte do instrumento antigo, o facto é que a sua contraparte moderna consegue, quando apropriadamente tocado, proporcionar praticamente toda a clareza e contraste exigidos pelo repertório do fortepiano, com evidentes ganhos tímbricos, mecânicos e de paleta dinâmica. Assim, o saldo desta manutenção da preferência pelo piano é positivo, não indo no entanto realmente contra a desiderabilidade da maior clareza de texturas.

\section{Projecção da estrutura formal}

Uma conclusão a extrair da leitura da literatura crítica de melhor qualidade é a de que uma eficaz gestão das propriedades formais ou estruturais da obra, i.e., a capacidade de um intérprete para projectar na audição do público os elementos da forma da obra e as suas articulações, é um dos principais méritos da execução de obras musicais. Um dos melhores exemplos da aplicação deste critério avaliativo é o domínio da gestão dos diferentes patamares de tensão e resolução, de modo a que o clímax principal de uma obra ou secção não seja nivelado com clímaxes secundários. Outro exemplo é o da chamada de atenção por parte do intérprete, na sua execução - e por meios diversos (dinâmica, rubato, etc.) -, para momentos centrais na articulação de formas musicais, como a recapitulação numa forma-sonata ou a transição de uma variação para a seguinte.

Naturalmente, não é o caso que, em todas as obras de todos os géneros da história da música clássica ocidental, as componentes estruturais sejam igualmente relevantes, nem do ponto de vista da pura análise composicional, nem, sobretudo, da perspectiva das possibilidades (e do interesse artístico) da sua realização em execuções. Assim, será mais provável que um crítico apele a critérios desta categoria na apreciação de uma execução de uma sinfonia de Bruckner do que na de um prelúdio de Chopin. Por outro lado, embora a com- 
ponente formal seja comparativamente tão importante na sinfonia como num moteto isorrítmico de Dufay, as limitações à projecção em execução no caso deste último são de uma natureza muito diferente, razão pela qual o apelo crítico a tal projecção - se ele existe de todo - é também bastante diferente. Como seria de esperar, expressão e forma não são completamente dissociáveis, havendo relações evidentes entre o modo como ambas se manifestam em execuções. Para ver isso, basta considerar o facto de que um dos recursos mais fundamentais de que o intérprete dispõe para delinear e projectar para um público a estrutura de uma obra ou secção consiste precisamente no doseamento da expressividade a aplicar a cada parâmetro, elemento ou evento musical.

Também aqui, parece-me, estamos na presença de um princípio - projectar a estrutura formal de uma obra - que só pode funcionar a favor do mérito de uma execução, ou, pelo menos, quase sempre funciona a favor desse mérito. Se duas execuções diferirem, grosso modo, "apenas" no facto de que uma projecta eficazmente essa estrutura e a outra não, será altamente provável que a que o faz será a melhor das duas. Trata-se, neste caso, e até de um modo mais evidente do que nos princípios anteriormente analisados, de um princípio que abona a favor do valor positivo da execução mesmo quando a estrutura formal da obra assim revelada não é dotada de grande interesse, sofisticação ou originalidade. Com efeito, pelo menos nas formas mais tradicionais - sonata, rondó, canção, variação, etc. -, a forma deve ser do conhecimento dos ouvintes experientes antes da escutarem uma nova obra, tratando-se antes de comparar o modo como um intérprete em particular projecta essa forma com o modo como outros o fazem, ou com o falhanço nessa projecção. Mais do que a aplicação de uma forma nova (ainda que isso possa ser o caso), o que importa do ponto de vista da forma musical estabelecida é compreender e apreciar o modo como o compositor tece o seu discurso musical em torno de um esqueleto pré-determinado. Mostrar isso ao público de um modo compatível com a musicalidade e a criatividade - ou mesmo potenciado por estas qualidades - é uma virtude da execução musical. ${ }^{12}$

\footnotetext{
${ }^{12}$ Não quero aqui ignorar o facto de que há discordância entre os musicólogos acerca da interpretação correcta da forma de algumas obras musicais do repertório, e logo, que ela existe entre os intérpretes dessas obras, pelo que o pluralismo
} 
Se precisarmos de um princípio mais geral de onde este possa ser derivado, à semelhança do que fiz acima, poderíamos sugerir que a virtude artística servida pelo meio da projecção da estrutura formal é em geral o de que algo que guia correctamente o ouvinte na sua audição é sempre bem-vindo. Claro que, como muitos outros princípios, e talvez todos em estética, este conhece excepções e pode ser suplantado por outros princípios quando não houver plena compatibilidade entre todos eles. Assim, uma execução em que o intérprete se esforce de tal modo nessa projecção que ponha em causa detalhes e efeitos importantes - por exemplo, à força de querer guiar o ouvinte para a identificação dos clímaxes mediante a subordinação de tudo o resto poderá, em função do repertório, estilo, e outras considerações, ser uma execução menos boa do que uma em que a atenção ao detalhe acompanhe uma atenção não tão grande à estrutura. No entanto, como já referi, estas excepções só seriam perigosas para uma posição mais fortemente objectivista do que a moderada que aqui defendo.

\section{A dicção na música vocal com texto}

Um último e breve exemplo de propriedade de execuções cuja posse só pode ser usada como razão a favor do valor positivo da mesma é o da clareza na dicção do texto cantado. Seja em música para solistas ou para conjunto, serão extremamente raros os casos em que essa propriedade possa ser usada para fundamentar um juízo negativo acerca da execução. Na verdade, acontece por vezes que essa qualidade é incompatível com outras qualidades igualmente positivas do canto, como a beleza do timbre, a largueza do espectro de dinâmicas usadas, a consistência e uniformidade da voz, e, mais particularmente, com o legato próprio de todo o canto tecnicamente educado na tradição em foco. Contudo, o facto contingente de que para alguns cantores é difícil, ou mesmo impossível, obter clareza na dicção do texto sem resultados pesadamente negativos no legato ou na emissão de notas agudas não deve ser usado como um argumento contra o

interpretativo será o caso nestas situações (agradeço ao Prof. John Rink por me alertar para este ponto (em comentário pessoal)). Tudo o que necessito de afirmar é que, na maioria dos casos, a compreensão da forma é relativamente pacífica, i.e., interpretativamente monística. 
princípio estético geral de que uma execução vocal é melhor se, em adição aos méritos que já exibe, também o texto for correctamente enunciado e perceptível pelo público, e nunca é pior por isso. Tal dificuldade poderá, isso sim, ser um argumento a favor da necessidade de aperfeiçoamento técnico da parte dos músicos em causa. Este princípio pode assim ser contado entre os princípios "fracos" ou suplantáveis conducentes ao maior valor estético ou artístico da execução musical, e talvez mesmo entre os menos fracos e suplantáveis de entre aqueles. ${ }^{13}$

\section{Uma objecção respondida: circularidade?}

Em conclusão, resta-nos considerar uma objecção pertinente à defesa do monismo moderado que apresentei. Consiste ela em detectar, nas expressões usadas para denotar as propriedades aqui referidas como sustentando esse monismo, um elemento de petição de princípio. Segundo a objecção, tais expressões contêm já aspectos valorativos de polaridade positiva. Assim, quando aqui se defende que as propriedades (razoavelmente) objectivas ou puramente descritivas denotadas por expressões tais como "clareza da polifonia/textura orquestral", "saliência dinâmica das entradas do tema da fuga" ou "relevo expressivo da melodia (acompanhada)" só (ou quase só, ceteris paribus e garantido o repertório adequado) poderão contar como valorizando positivamente as execuções que exibem tais propriedades, o oponente diria que a conclusão já estava de algum modo contida nas premissas, uma vez que, supostamente, só em virtude de uma avaliação positiva prévia se pode atribuir com correcção essas propriedades a execuções.

Contudo, não me parece que a objecção colha. Com efeito, qual das expressões da pequena lista acima contém um elemento indelevelmente avaliativo? Clareza? Mas o predicado 'claro' atribuído, por exemplo, a uma voz (cantada), é puramente descritivo. Que Emma Kirkby tem uma voz clara e Jessye Norman tem uma voz escura são afirmações (metaforicamente, talvez, mas contextualmente con-

\footnotetext{
${ }^{13}$ Observe-se que, sintomaticamente, a enunciação clara e perceptível do texto parece ser reconhecida pelos críticos como uma virtude performativa mesmo quando esses críticos, ou o público, não dominam a língua do texto a ser cantado.
} 
sensualmente) verdadeiras que não comprometem ninguém que as afirme com juízos de valor - embora, dependendo das sensibilidades individuais, possam justificar que será provável que certos sujeitos apreciem mais uma dessas vozes de soprano do que a outra. Mais a propósito, 'claro' aplicado a uma textura musical parece ser tão puramente descritivo quanto a aplicação acima, sendo um facto contingente que (praticamente) todos os ouvintes competentes apreciem uma maior clareza na textura (com as qualificações já referidas). Tal facto pode mudar no futuro, mas o meu objectivo não é evidentemente defender que é uma verdade conceptual ou analítica que clarificar de uma textura em execução é melhor do que não o fazer, nem sequer que se trate de algum universal estético - embora isso não seja propriamente impossível. O mesmo é o caso relativamente a propriedades como as referidas pelas expressões 'saliência' - é algo ipso facto esteticamente bom só por ser saliente? - e 'relevo expressivo' - nem todo o parâmetro musical afecta positivamente o valor de uma execução apenas porque lhe é dado relevo expressivo, e alguns contribuem mesmo negativamente se lhes for conferido tal relevo. ${ }^{14}$

A objecção poderá, não obstante, ter maior força se incidir sobre o princípio mais geral que enunciei como uma fonte de onde poderiam derivar pelo menos alguns dos princípios mais particulares acima, o princípio que afirma que o que é musicalmente interessante na composição deve ser evidenciado em execução. O predicado 'interessante' tem evidentemente uma carga valorativa. No entanto, creio que é possível mostrar que há critérios razoavelmente objectivos e universais para identificar, dados os parâmetros relevantes, que eventos ou propriedades musicais são interessantes. De facto, tratase de algo que é aprendido desde cedo na educação musical, quer do ouvinte, quer do intérprete. A franja de relatividade na determinação do que é musicalmente interessante é real, mas não demasiado larga. Critérios objectivos, ou pelo menos largamente consensuais, para identificar graus de relevância musical de elementos como a presença de um cantus firmus, a existência de linhas melódicas dignas de atenção no interior de uma textura ou a antecipação de um tema de uma secção climática numa secção anterior estão em geral disponíveis a

${ }^{14}$ Suponha-se, por exemplo, que um intérprete decide dar relevo dinâmico aos ritmos pontuados num Nocturno de Chopin. 
uma boa parte do público musicalmente educado e experiente em mais do que uma audição informada de cada obra, sem o prejuízo de que abordagens mais sofisticadas - musicológicas - possam revelar algumas qualificações a tal objectividade, mas apenas em alguns casos, não certamente na maioria.

António Lopes Universidade de Lisboa e Grupo LanCog

\section{Referências}

Berry, Wallace. 1989. Musical Structure and Performance. New Haven: Yale University Press.

Cook, Nicholas. 2003. Writing on Music or Axes to Grind: road rage and musical community. Music Education Research, Vol. 5, No. 3, Novembro 2003, 249-261.

Kivy, Peter. 1995. Authenticities. Philosophical reflections on musical performance. Ithaca NY: Cornell University Press.

Levinson, Jerrold. 1987. Evaluating Musical Performance. In Jerrold Levinson, Music, Art and Metaphysics: Essays in Philosophical Aesthetics. Ithaca NY: Cornell University Press, 376-392.

Lopes, António. 2005. Musical Works and Performance Evaluation. Postgraduate Online Journal of Aesthetics (British Society of Aesthetics), 2: 2 (Agosto 2005)

(https://leopard.ncl.ac.uk/BSA/PJAArchive.aspx)

Lopes, Antonio. 2006. Relativismo na Avaliação de Execuções Musicais. Philosophica (Revista do Departamento de Filosofia da Universidade de Lisboa), $\mathrm{n}^{\circ} 27$.

Lopes, António. 2010. O Valor de um Bach Autêntico; um Estudo sobre o Conceito de Autenticidade na Execução de Obras Musicais. Lisboa: Fundação Calouste Gulbenkian.

Narmour, Eugene. 1988. On the Relationship of Analytical Theory to Performance and Interpretation, in Explorations in Music, the Arts, and Ideas, ed. by E. Narmour and R. Solie. New York: Pendragon Press, 1988, 317-340.

Sibley, Frank. 1989. Aesthetic Concepts. In Aesthetics. A Critical Anthology, ed. by George Dickie et al. New York: St. Martin's Press, 356-374. 